University of Nebraska - Lincoln

DigitalCommons@University of Nebraska - Lincoln

9-13-2005

\title{
Characterization of waxy grain sorghum lines in relation to granule-bound starch synthase
}

\author{
J. F. Pedersen \\ USDA, ARS, NPA Wheat, Sorghum and Forage Research, jpedersen1@unl.edu
}

S. R. Bean

USDA, ARS, NPA, GMPRC

R. A. Graybosch

USDA, ARS, NPA Wheat, Sorghum and Forage Research, bob.graybosch@ars.usda.gov

S. H. Park

Kansas State University, Manhattan, Kansas

M. Tilley

USDA, ARS, NPA, GMPRC

Follow this and additional works at: https://digitalcommons.unl.edu/usdaarsfacpub

Part of the Agricultural Science Commons

Pedersen, J. F.; Bean, S. R.; Graybosch, R. A.; Park, S. H.; and Tilley, M., "Characterization of waxy grain sorghum lines in relation to granule-bound starch synthase" (2005). Publications from USDA-ARS / UNL Faculty. 164.

https://digitalcommons.unl.edu/usdaarsfacpub/164

This Article is brought to you for free and open access by the U.S. Department of Agriculture: Agricultural Research Service, Lincoln, Nebraska at DigitalCommons@University of Nebraska - Lincoln. It has been accepted for inclusion in Publications from USDA-ARS / UNL Faculty by an authorized administrator of DigitalCommons@University of Nebraska - Lincoln. 


\title{
Characterization of waxy grain sorghum lines in relation to granule-bound starch synthase ${ }^{\star}$
}

\author{
J.F. Pedersen ${ }^{1, *}$, S.R. Bean ${ }^{2}$, R.A. Graybosch ${ }^{1}$, S.H. Park ${ }^{3} \&$ M. Tilley ${ }^{2}$ \\ ${ }^{1}$ USDA, ARS, NPA Wheat, Sorghum and Forage Research, 344 Keim Hall, University of Nebraska-Lincoln, \\ Lincoln, NE 68583-0937, USA; ${ }^{2}$ USDA, ARS, NPA, GMPRC, 1515 College Avenue, Manhattan, KS 66502, USA; \\ ${ }^{3}$ Kansas State University, Department of Grain Science and Industry, Manhattan, KS 66506, USA (*author for \\ correspondence: e-mail: jfp@unlserve.unl.edu)
}

Received 14 February 2005; accepted 29 March 2005

Key words: amylose, amylopectin, granule bound starch synthase, sorghum, starch, waxy

\section{Summary}

The waxy phenotype, associated with endosperm containing little or no amylose, has been recognized in sorghum (Sorghum bicolor L. Moench) since 1933. Although variants of the waxy gene are well characterized in other cereals, the waxy trait has been assumed to be controlled by a single allele, $w x$, in sorghum. Recent improvements in technologies encourage re-examination of the waxy sorghums. The objectives of this research were therefore to identify and characterize sorghum lines with differing waxy alleles and to describe the actions of those alleles in crosses. Grain of eight waxy sorghum lines (BTxARG1, BTx630, Tx2907, B.9307, 94C274, 94C278, 94C289, 94C369), three wild-type checks (BWheatland, RTx430, BN122), and $\mathrm{F}_{2}$ families from crosses among a subset of these lines were evaluated for presence or absence of granule-bound starch synthase (GBSS), the gene product of the $w x$ locus, and wild-type vs. waxy endosperm. The $\mathrm{F}_{2}$ segregation ratios were tested for fit to a 3:1 ratio using Chi-square analyses. Two distinctly different naturally occurring waxy alleles were identified: One with no GBSS (GBSS-), and one with apparently inactive GBSS present (GBSS+). We propose that the waxy allele with no GBSS be designated $w x^{a}$, and that waxy allele with apparently inactive GBSS present be designated $w x^{b}$. These two alleles are located in close proximity on the waxy locus. The $w x^{b}$ allele is dominant to the $w x^{a}$ allele in terms of GBSS production, and both are recessive to the wild-type $W x$ in terms of amylose content.

Abbreviations: GBSS: granule bound starch synthase; SDS-PAGE: Sodium dodecyl sulphate polyacrylamide gel electrophoresis

\section{Introduction}

The waxy phenotype in cereal grains is associated with endosperm starch containing little or no amylose due to the absence or inactivation of granule-bound starch synthase. The waxy gene is perhaps best understood in maize (Zea mays L.), with the gene having been cloned (Shure et al., 1983) and sequenced (Klösgen et al., 1986), a fine structure genetic map of mutations

^The U.S. Government's right to retain a non-exclusive, royalty-free license in and to any copyright is acknowledged. developed (Nelson, 1968) and strong correlation between genetic and physical maps established (Wessler \& Varagona, 1985). Waxy genes have been well characterized in wheat (Triticum aestivum L.) (Ainsworth et al., 1992), rice (Oryza sativa L.) (Hirano \& Sano, 1991), barley (Hordeum vulgare L.), (Rohde et al., 1988), and foxtail millet (Setaria italica (L.) P. Beauv) (Fukunaga et al., 2002), and have been cloned in sorghum (Sorghum bicolor L. Moench) (Hsieh et al., 1996a).

The waxy phenotype has been recognized in sorghum since 1933 when the gene symbol wx was 
assigned to this trait (Karper, 1933). Although variants of the waxy gene and phenotype are well established in other cereals, the waxy trait has been assumed to be controlled by a single allele, $w x$, in sorghum (Rooney, 2000). This may be due in part to reliance on subjective visual assessment of endosperm fracture patterns for classification of sorghum lines as waxy or wild-type.

Recent improvements in staining methodologies to detect the presence or absence of amylose in sorghum grain and pollen (Pedersen et al., 2004) encourage reexamination of the hypothesis that the waxy trait is controlled by a single allele, $w x$, in sorghum. The report of an induced waxy mutation in sorghum with reduced granule-bound starch synthase (GBSS) activity (Hsieh et al., 1996a,b) and a preliminary report of existence of waxy sorghum lines differing in presence or absence of GBSS (McIntyre, 1998) strongly suggest that variants of the waxy gene exist in sorghum as in other cereals. Such variation could have importance for geneticists, breeders, and industry consumers of waxy sorghum. Therefore the objectives of the research described herein were to identify and characterize sorghum lines potentially carrying different waxy alleles and to describe the actions of those alleles in crosses.

\section{Materials and methods}

Grain of eight waxy sorghum lines (BTxARG1, BTx630, Tx2907, B.9307, ${ }^{1}$ 94C274, 94C278, 94C289, 94C369) and three wild-type checks (BWheatland, RTx430, BN122) were evaluated for presence or absence of GBSS using two techniques, sodium dodecyl sulphate polyacrylamide gel electrophoresis (SDS-PAGE) and immunoblotting. Several lines are related by pedigree. The waxy line $94 \mathrm{C} 274$ was derived from the cross BTx630 $\times$ BTx629, and 94C369 derives from the cross $\mathrm{R} 338 \mathrm{~W} \times(\mathrm{RT} \times 430 \times$ 77CS1). The exact pedigree of B.9307 is not available, but it is similar to BTxARG1 (Rooney, 2002, Personal communication). SDS-PAGE of proteins extracted form purified starch granules was carried out as described in Gaines et al. (2000). Immuno-blots were carried out using the method of Towbin et al. (1979). Immuno-blots were probed with an antibody to wheat GBSS (Graybosch et al., 1999) using standard protocols. Amylose content was determined using the Megazyme amylose/amylopectin assay kit

\footnotetext{
${ }^{1}$ B.9307, 94C274, 94C278, 94C289, 94C369 are experimental waxy sorghum lines graciously provided by Dr. William Rooney, Texas A\&M University.
}

(Megazyme, Bray, Ireland). Presence of $>2 \%$ amylose was assumed to be indicative of active GBSS.

Hand emasculations were made among selected waxy lines (BTx630, Tx2907, BTxAGR1, and B.9307) and the wild-type check BWheatland. The $\mathrm{F}_{1}$ plants were visually confirmed as hybrids, and $\mathrm{F}_{2}$ generation pollen and seed collected for use in testing segregation ratios and for fine mapping. Pollen and seed were stained with potassium iodine as per Pedersen et al. (2004), and presence (+) or absence (-) of GBSS was determined using SDS-PAGE as above (Gaines et al., 2000).

The $\mathrm{F}_{2}$ segregation ratios of wild-type vs. waxy endosperm, and GBSS + vs. GBSS - in individual seeds were tested for fit to a 3:1 ratio using Chi-square analyses (SAS, 1999). Estimation of genetic map distance $(1 \%$ crossover $=1 \mathrm{cM}$ genetic distance $)$ was attempted as indicated by recovery of revertants to the wild-type phenotype in the $\mathrm{F}_{2}$ generation of waxy (GBSS + ) $\times$ waxy (GBSS-) crosses using pollen (Nelson, 1962) and grain. For Chi-square analyses for waxy vs. wildtype, at least 48 individual seeds were tested per $\mathrm{F}_{2}$ family, and for GBSS - vs. GBSS + 59 individual seeds were tested per $\mathrm{F}_{2}$ family. For fine mapping, 1000 seeds were tested for waxy vs. wild-type per $\mathrm{F}_{2}$ family.

\section{Results and discussion}

Results indicated the existence of at least two distinctly different naturally occurring waxy alleles in the 11 sorghum lines examined (Table 1, Figures 1 and 2): BWheatland, BN122, and RTx430 are wild-type (23\% amylose) with active GBSS. BTx630, Tx2907, 94C274, 94C278, 94C289, and 94C369 are waxy

Table 1. Characterization of 11 sorghum lines for amylose, GBSS, and response to a wheat GBSS antibody

\begin{tabular}{llll}
\hline Sorghum line & Amylose $(\%)$ & GBSS presence & Antibody reaction \\
\hline BWheatland & 23.0 & Yes & Yes \\
BN122 & 22.6 & Yes & Yes \\
RTx430 & 23.5 & Yes & Yes \\
BTxAGR1 & 1.8 & Yes & Yes \\
BTx630 & 1.5 & No & No \\
Tx2907 & 1.3 & No & No \\
B.9307 & 1.1 & Yes & Yes \\
$94 C 274$ & 1.3 & No & No \\
94C278 & 1.4 & No & No \\
94C289 & 1.3 & No & No \\
$94 C 369$ & 0.9 & No & No \\
\hline
\end{tabular}




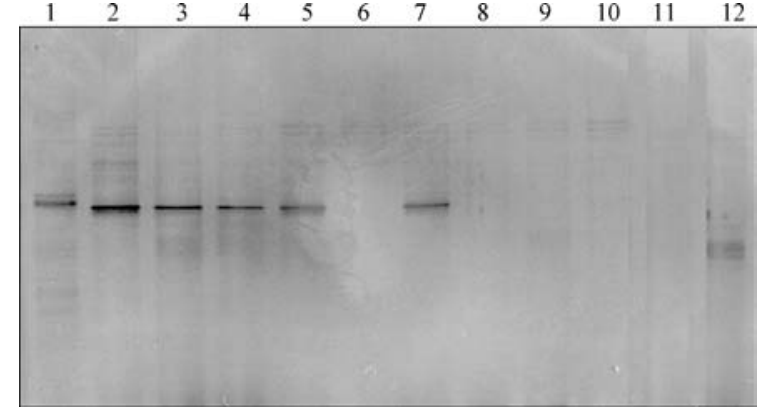

Figure 1. SDS-PAGE of extracts from 11 sorghum lines and a GBSS positive wheat check. Lane 1: Scout 66 (wild-type wheat); lanes 2, 3, 4: RTx430, BN122, BWheatland (wild-type sorghums); lanes 512: BTxAgr1, BTx630, B.9307, 94C274, Tx2907, 94C289, 94C278, 94C369 (waxy sorghums).

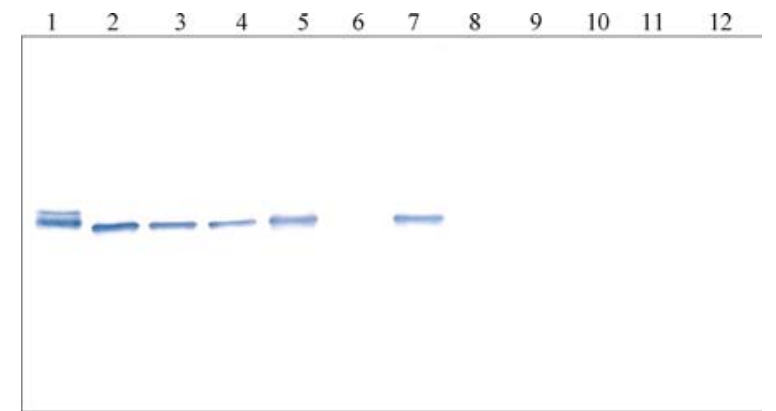

Figure 2. Immunoblots for GBSS in 11 sorghum lines using a wheat GBSS antibody. Lane 1: Scout 66 (wild-type wheat); lanes 2-4: RTx430, BN122, BWheatland (wild-type sorghums); lanes 5-12: BTxAgr1, BTx630, B.9307, 94C274, Tx2907, 94C289, 94C278, 94C369 (waxy sorghums).

( $<2 \%$ amylose) with no detectable GBSS. BTxAGR1 and B.9307 are waxy $(<2 \%$ amylose) but with detectable but apparently inactive GBSS. On SDS-PAGE and immunoblots, the apparently inactive GBSS migrates to the same position as wild-type GBSS (Figures 1 and 2). Although not definitive in terms of establishing the genetic relationships among these alleles, it is significant to note that pedigree relationships involving the absence or presence of GBSS in waxy sorghum lines were maintained.

Observed segregation ratios for wild-type vs. waxy endosperm fit an expected 3:1 ratio with wildtype being dominant to waxy endosperm in $\mathrm{F}_{2}$ seed from the hand emasculation crosses between BTx630 (GBSS-), Tx2907 (GBSS-), BTxAGR1 (GBSS+), and B.9307 (GBSS+), and BWheatland (Wild-type) (Table 2) with one exception. In the cross BWheatland $\times$ Tx2907, the waxy phenotype occurred at lower frequency (5:43) in initial analyses than could be explained with a simple 3:1 segregation ratio. The sam-
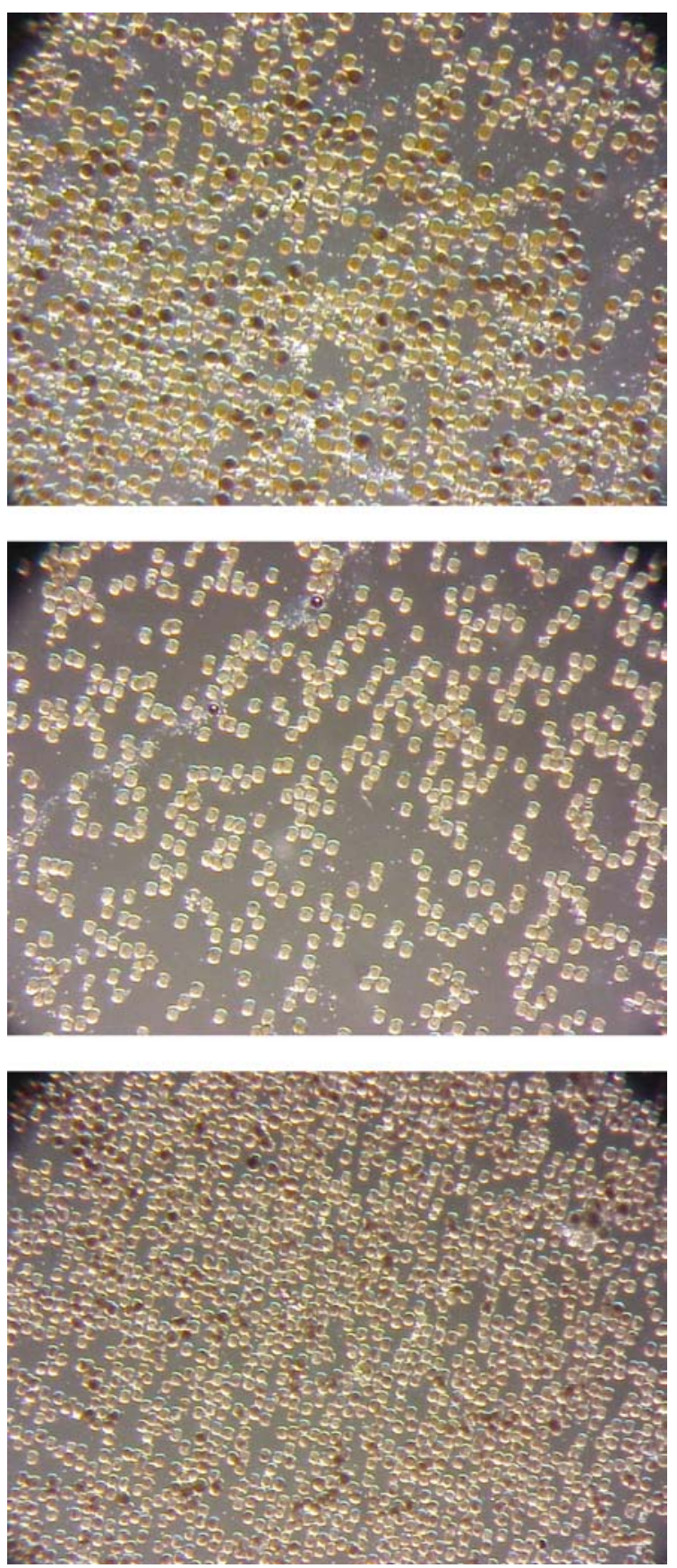

Figure 3. $\mathrm{F}_{2}$ pollen from Tx2907 × B.9307 (top), Tx2907, and B. 9307 (bottom) varies in intensity of potassium iodine staining $(20 \times$ magnification).

ple size of that $\mathrm{F}_{2}$ population was increased to 192 and analyses repeated with similar results (33:159). Other possible segregation ratios, $12: 7$ and $15: 1$, were tested but provided even poorer fit as indicated by Chi-square analyses. It is worth noting that the reciprocal cross, 
Table 2. Chi-square tests for goodness of fit to a 1:3 ratio of waxy:wild-type endosperm in $\mathrm{F}_{2}$ seed of wild-type $\times$ waxy (GBSS+), and wild-type $\times$ waxy $(\mathrm{GBSS}-)$ crosses

\begin{tabular}{|c|c|c|c|c|c|}
\hline Pedigree & Description & $\begin{array}{l}\text { Waxy } \\
\text { (number) }\end{array}$ & $\begin{array}{l}\text { Wild-type } \\
\text { (number) }\end{array}$ & $\chi^{2}$ & Prob. $\chi^{2}$ \\
\hline $\mathrm{F}_{2}$ BWheatland $\times$ BTxAgr 1 & wild-type $\times$ waxy $(\mathrm{GBSS}+$ ) & 14 & 34 & 0.44 & 0.51 \\
\hline $\mathrm{F}_{2}$ BTxAgr1 $\times$ BWheatland & waxy $(\mathrm{GBSS}+) \times$ wild-type & 14 & 34 & 0.44 & 0.51 \\
\hline $\mathrm{F}_{2}$ BWheatland $\times$ B.9307 & wild-type $\times$ waxy $(\mathrm{GBSS}+)$ & 14 & 34 & 0.44 & 0.51 \\
\hline $\mathrm{F}_{2}$ B.9307 $\times$ BWheatland & waxy $(\mathrm{GBSS}+) \times$ wild-type & 14 & 34 & 0.44 & 0.51 \\
\hline $\mathrm{F}_{2}$ BWheatland $\times$ BTx 630 & wild-type $\times$ waxy (GBSS-) & 10 & 38 & 0.44 & 0.51 \\
\hline $\mathrm{F}_{2}$ BTx $630 \times$ BWheatland & waxy $(\mathrm{GBSS}-) \times$ wild-type & 15 & 33 & 1.00 & 0.32 \\
\hline$F_{2}$ BWheatland $\times$ Tx2907 & wild-type $\times$ waxy $(\mathrm{GBSS}-$ ) & 33 & 159 & 6.25 & 0.01 \\
\hline$F_{2}$ Tx2907 × BWheatland & waxy $(\mathrm{GBSS}-) \times$ wild-type & 11 & 39 & 0.24 & 0.62 \\
\hline
\end{tabular}

Tx2907 $\times$ BWheatland did fit the expected 3:1 segregation ratio, suggesting that the lack of fit to the $3: 1$ ratio observed for this single cross is associated with the use of Tx2907 as a pollen source.

Staining of pollen to detect revertants to the wildtype phenotype in the $F_{2}$ populations from waxy GBSS $+x$ waxy GBSS - was not useful due to the presence of numerous darker staining pollen grains in the progeny of waxy GBSS $-x$ waxy GBSS + crosses and waxy GBSS+ lines (Figure 3). These darker staining pollen grains were not as dark as seen in the wildtype (Figure 4) and apparent intensity of staining was greatly influenced by minor adjustments of light directed to the microscope stage. While the observation of the darker staining pollen grains in GBSS $-x$ waxy GBSS + crosses and GBSS + lines is indicative of some GBSS+ effect in sorghum pollen, our current sorghum

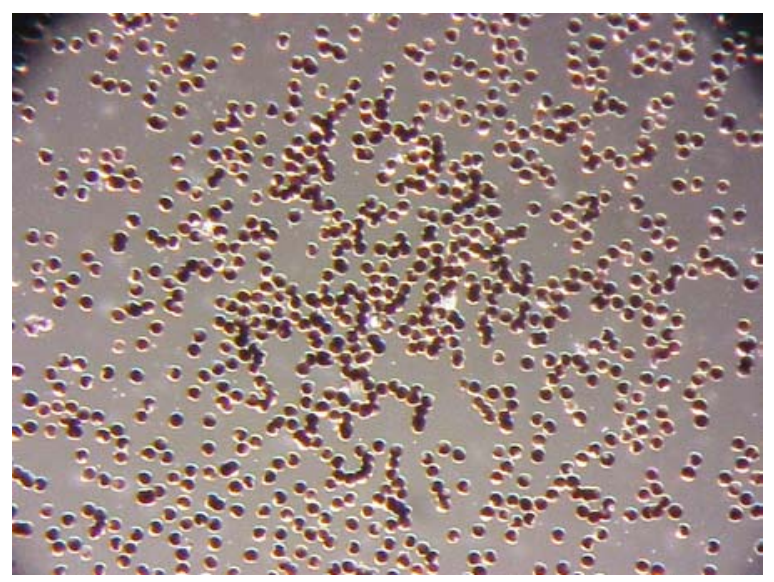

Figure 4. Pollen from Wheatland (wild-type) stains uniformly dark with potassium iodine $(20 \times$ magnification $)$. pollen staining technique is not sensitive enough to describe it. Differences in expression of waxy alleles in sorghum endosperm and pollen would not, however, be unexpected. Tissue specific expression of waxy genes has been reported in rice (Hirano \& Sano, 2000) and wheat (Vrinten \& Nakamura, 2000).

One thousand ninety-eight $\mathrm{F}_{2}$ seed from two waxy GBSS $-x$ waxy GBSS + crosses were stained and examined for revertants to the wild-type phenotype. No wild-type revertants were observed (Table 3). Assuming that detection of a single revertant per population would have been indicative of a $0.1 \%$ crossover rate, the map distance of these GBSS - and GBSS+ alleles is less than $0.1 \mathrm{cM}$. A preliminary report describing an ethyl methanesulfonate induced waxy mutation of sorghum with a $60 \mathrm{kD}$ protein still recognizable by waxy protein antibody indicated the cause was single point mutation in the ORF with a $G$ to $A$ transition (Hsieh et al., 1996b). Although not direct evidence, that preliminary report supports our conclusion that the naturally occurring waxy GBSS - and waxy GBSS+ alleles are separated by less than $0.1 \mathrm{cM}$.

Segregation ratios for waxy GBSS - and waxy GBSS + alleles fit a ratio of 3:1 with waxy GBSS+ being dominant to waxy GBSS - in $\mathrm{F}_{2}$ seed from the hand emasculation crosses between BTx630 (GBSS-) and BTxAGR1 (GBSS+), and between Tx2907 (GBSS-), and B.9307 (GBSS+) (Table 4, Figure 5). Reciprocal crosses gave nearly identical results again indicating simple dominance of the GBSS+ allele to the GBSSallele in waxy $x$ waxy crosses.

\section{Conclusions}

Based on the study of a set of waxy sorghum lines (BTxARG1, BTx630, Tx2907, B.9307, 94C274, 
Table 3. Non-recovery of wild-type revertants in $\mathrm{F}_{2}$ seed from waxy (GBSS+) $\times$ waxy (GBSS-) crosses

\begin{tabular}{llll}
\hline Pedigree & Description & $\begin{array}{l}\text { Waxy } \\
\text { (number) }\end{array}$ & $\begin{array}{l}\text { Wild-type } \\
\text { (number) }\end{array}$ \\
\hline F $_{2}$ BTx630 $\times$ BTxAgr1 & waxy $($ GBSS - ) $\times$ waxy $($ GBSS + ) & 1098 & 0 \\
$F_{2}$ Tx2907 $\times$ B.9307 & waxy $($ GBSS - ) $\times$ waxy $($ GBSS + ) & 1098 & 0
\end{tabular}

Table 4. Chi-square tests for goodness of fit to a 1:3 ratio of absence:presence of GBSS protein in $\mathrm{F}_{2}$ seed of waxy (GBSS+) $\times$ waxy (GBSS - ) crosses

\begin{tabular}{|c|c|c|c|c|c|}
\hline Pedigree & Description & GBSS - (number) & GBSS + (number) & $\chi^{2}$ & Prob. $\chi^{2}$ \\
\hline $\mathrm{F}_{2} \mathrm{BT} \times \mathrm{Agr} 1 \times \mathrm{BT} \times 630$ & waxy $(\mathrm{GBSS}+) \times$ waxy $(\mathrm{GBSS}-)$ & 13 & 46 & 0.28 & 0.60 \\
\hline $\mathrm{F}_{2} \mathrm{BT} \times 630 \mathrm{~B} \times \mathrm{TxAgr} 1$ & waxy $(\mathrm{GBSS}-) \times$ waxy $(\mathrm{GBSS}+)$ & 12 & 47 & 0.68 & 0.41 \\
\hline $\mathrm{F}_{2}$ B. $9307 \times \mathrm{T} \times 2907$ & waxy $(\mathrm{GBSS}+) \times$ waxy $(\mathrm{GBSS}-)$ & 17 & 42 & 0.46 & 0.50 \\
\hline $\mathrm{F}_{2} \mathrm{~T} \times 2907 \times \mathrm{B} .9307$ & waxy $(\mathrm{GBSS}-) \times$ waxy $(\mathrm{GBSS}+)$ & 13 & 46 & 0.28 & 0.60 \\
\hline
\end{tabular}

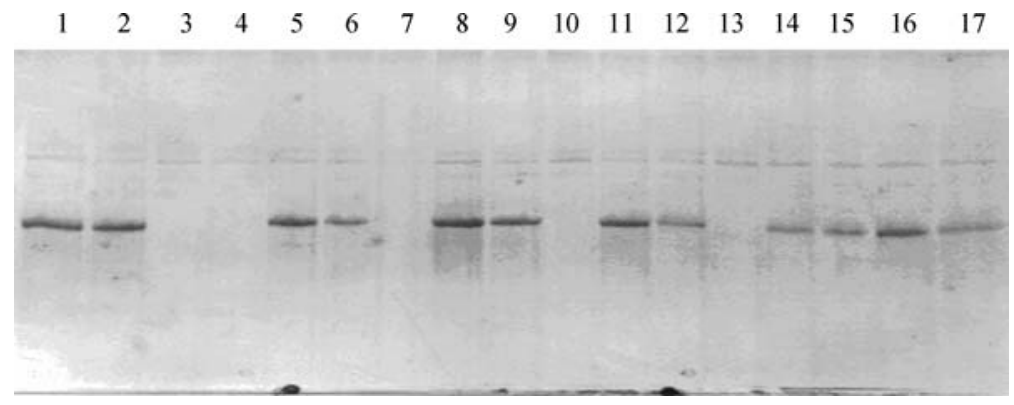

Figure 5. SDS-PAGE of extracts from Tx630 (GBSS-) and TxAgr1 (GBSS+) and F2 seed from the cross Tx630 × TxAgr1. Lanes 1-6: F2 Tx630 × TxAGR1; lane 7: Tx630 (GBBS-); lane 8: TxAgr1 (GBBS+); lanes 9-17: F2 Tx630 × TxAGR1.

94C278, 94C289, 94C369), two distinctly different naturally occurring waxy alleles were identified. We propose that the waxy GBSS - allele (with no GBSS present) be designated $w x^{a}$, and that the waxy GBSS+ (with apparently inactive GBSS present) allele be designated $w x^{b}$. These two alleles are located in close proximity on the waxy locus. The $w x^{b}$ allele is dominant to the $w x^{a}$ allele in terms of GBSS production, and both are recessive to the wild-type $W x$ in terms of amylose content. However, in a single cross, BWheatland $\times$ Tx2907, segregation ratios could not be fit to 3:1 suggesting that the $w x$ allele may be having some unknown effect on Tx2907 pollen.

The discovery of naturally occurring waxy alleles within a limited subset of waxy sorghum lines is in agreement with observations of multiple waxy alleles in this transposon rich locus of other grain species. This research clearly establishes sorghum as a species with naturally occurring diversity at this locus, and high- lights the need to further understand and explore the waxy locus in sorghum.

\section{References}

Ainsworth, C., J. Clark \& J. Balsdon, 1992. Expression, organization and structure of the genes encoding the waxy protein (granulebound starch Synthase) in wheat. Plant Mol Biol 22: 67-72.

Fukunaga, K., M. Kawase \& K. Kato, 2002. Structural variation in the waxy gene and differentiation in foxtail millet [Setaria italica (L.) P. Beauv.]: Implications for multiple origins of the waxy phenotype. Mol Genet Genomics 268: 214-222.

Gaines, C.S., M.Ö. Raeker, M. Tilley, P.L. Finney, J.D. Wilson, D.B. Bechtel, R.J. Martin, P.A. Seib, G.L. Lookhart \& T. Donelson, 2000. Associations of starch gel hardness, granule size, waxy allelic expression, thermal pasting, milling quality, and kernel texture of 12 soft wheat cultivars. Cereal Chem 77(2): 163-168.

Graybosch, R.A., K.J. Schemmerhorn \& J.H. Skerritt, 1999. An enzyme-linked immunosorbent assay for the identification of wheats carrying null alleles at genetic loci encoding the granulebound starch synthase. J Cereal Sci 30: 159-163. 
Hirano, H. \& Y. Sano, 1991. Molecular characterization of the waxy locus of rice (Oryza sativa). Plant Cell Physiol 32: 989-997.

Hirano, H. \& Y. Sano, 2000. Comparison of waxy gene regulationin the endosperm and pollen in Oriza sativa L. Genes Genet Syst 75: 245-249.

Hsieh, J., C. Liu \& Y.C. Hsing, 1996a. Molecular cloning of a sorghum cDNA (Accession No. U23945) encoding the seed waxy protein (PGR96-119). Plant Physiol 112: 1735.

Hsieh, J.S., C.L. Lin, Y.C. Huang \& Y.C. Hsing, 1996b. An EMSinduced sorghum waxy mutant that still express the $60 \mathrm{kD}$ waxy protein. Plant Phys 111(2): 741. Suppl. Jun 1996.

Karper, R.E., 1933. Inheritance of waxy endosperm in sorghum. J Hered 24: 257-262.

Klösgen, R.B., A. Gierl, Z. Schwarz-Sommer \& H. Saedler, 1986. Molecular analyses of the waxy locus of Zea mays. Mol Gen Genet 203: 237-244.

McIntyre, L., 1998. Characterization of waxy alleles in sorghum. In Proceedings of the Plant and Animal Genome VI Conference, Jan. 18-22, San Diego, CA.

Nelson, O.E., 1962. The waxy locus in maize. I. Intralocus recombination frequency estimates by pollen and by conventional analyses. Genetics 47: 737-742.

Nelson, O.E., 1968. The waxy locus in maize. II. The location of the controlling element alleles. Genetics 60: 507-524.
Pedersen, J.F., S.R. Bean, D.L. Funnell \& R.A. Graybosch, 2004. Rapid iodine staining techniques for identifying the waxy phenotype in sorghum grain and waxy genotype in sorghum pollen. Crop Sci 44: (in press).

Rohde, W., D. Becker \& F. Salamini, 1988. Structural analysis of the waxy locus from Hordeum vulgare. Nucleic Acids Res 16: 7185-7186.

Rooney, W.L., 2000. Genetics and cytogenetics. In: C.W. Smith \& R.A. Frederiksen (Eds.), Sorghum: Origin, History, Technology, and Production, pp. 261-308. John Wiley \& Sons., Inc. New York, NY.

SAS User's Guide, 1999. Statistics, Version 8 Edition. SAS Inst., Inc., Cary, NE.

Shure, M., S. Wessler \& N. Fedoroff, 1983. Molecular identification and isolation of the waxy locus in maize. Cell 35: 225-233.

Towbin, H., T. Staehelin \& J. Gordon, 1979. Electrophoretic transfer of proteins from polyacrylamide gels to nitrocellulose sheets: Procedure and some applications. Proc Natl Acad Sci USA 76: 4350-4354.

Vrinten, P.L. \& T. Nakamura, 2000. Wheat granual-bound starch synthase I and II are encoded by separate genes that are expressed in different tissues. Plant Phys 122: 255-263.

Wessler, S.R. \& M.J. Varagona, 1985. Molecular basis of mutations at the waxy locus of maize correlation with the fine structure genetic map. Proc Natl Acad Sci USA 82: 4177-4181. 